Thieme journals fulfill your need for contemporary resources

A diverse group of award-winning Editors complement our journals in a vast variety of specialties.
Read and submit

http://open.thieme.com

(https://adfarm1.adition.com/redi?

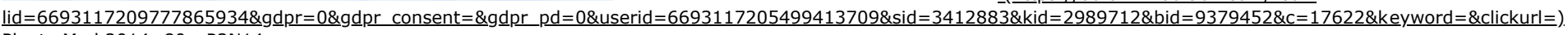
Planta Med 2014; 80 - P2N14 DOI: $10.1055 / \mathrm{s}-0034-1394834$

\title{
Incorporation of neuroprotective compounds of Hypericum perforatum in polymeric nanoparticles
}

A Oliveira $\underline{\mathbf{1}}, \underline{\mathbf{2}}$, C Pinho $\underline{\mathbf{1}}, \underline{\mathbf{2}}$, B Sarmento $\underline{\mathbf{3}}, \underline{\mathbf{4}}$, A Dias $\underline{\mathbf{1}}$

${ }^{\mathbf{1}}$ Centre for the Research and Technology of Agro-Environment and Biological Sciences (CITAB-UM), AgroBioPlant Group, Department of Biology, University of Minho, Portugal

${ }^{2}$ Núcleo de Investigação e Informação em Farmácia (NIF), Centro de Investigação em Saúde e Ambiente (CISA), Escola Superior de Tecnologia de Saúde do Porto - Instituto Politécnico do Porto (ESTSP-IPP), Vila Nova de Gaia, Portugal

${ }^{3}$ CESPU, IINFACTS - Instituto de Investigação e Formação Avançada em Ciências e Tecnologias da Saúde, Instituto Superior de Ciências da Saúde-Norte, GandraPRD, Portugal

${ }^{4}$ INEB - Instituto de Engenharia Biomédica, University of Porto, Porto, Portugal

Congress Abstract

Hypericum perforatum extracts have been used for their antidepressive effects. Recently, a selected fraction (HP) isolated from these extracts and containing compounds like quercetin and biapigenin proved to be neuroprotective $[1,2]$. The present work aims to i- develop a method to isolate HP in a pure and large scale, ii- characterize the cellular toxicity/protection of HP, and iii- incorporation of HP in PCL nanoparticles. After maceration of $H$. perforatum dry leaves with methanol $80 \%(\mathrm{~V} / \mathrm{V})$, a liquid-liquid extraction with diethyl ether was performed. This fraction was further concentrated and subjected to Sephadex LH-20 column chromatography. A selected fraction was collected, concentrated, and pass by a Polyamide CC6 column. With this process up to $200 \mathrm{mg}$ of pure HP were obtained, containing mainly quercetin and biapigenin (1:1 w/w, HPLC-DAD), without any traces of hypericins, compounds with unwanted side-effects. HP showed strong antiradicalar activity (DPPH assay), with a $\mathrm{EC}_{50}$ of $3,96 \mu \mathrm{g} / \mathrm{mL}$. The HP cellular toxicity was tested in a range of concentrations of $1-100 \mu \mathrm{g} / \mathrm{mL}$, in several cell lines. Toxicity was observed for HepG2 (human hepatic cells) and HDMEC (human dermal microvascular endothelial cells) at 25 and $100 \mu \mathrm{g} / \mathrm{mL}$, respectively. No toxicity was observed for U87 cells (brain human gliobastoma). HP was encapsulated in PCL polymeric nanoparticles (NP) by solvent displacement technique and NPs were physically characterised by laser doppler anemometry. NP size range from $185-195 \mathrm{~nm}$; zeta potential was of $-20 \mathrm{mV} \pm 1.23$. HP incorporation efficiency, determined by HPLC, was of $99.29 \% \pm 0.13$. NP toxicity was also tested in HepG2, HDMEC and U87 cells. Toxicity was observed in HDMEC and U87 cells, at concentrations higher than 200 and 100 $\mu \mathrm{g} / \mathrm{mL}$, respectively. Several assays still need to be performed in order to fully determine the neuroprotective potential of these compounds and specifically of nanoparticles containing them.

Acknowledgements: This work was supported by Fundação para a Ciência e Tecnologia (FCT), projects PTDC/AGRALI/105169/2008, PEst-OE/AGR/UI4033/2014, and by Instituto Politécnico do Porto (Programa de Formação Avançada de Docentes).

Keywords: Hypericum perforatum, quercetin, biapigenin, toxicity, neuroprotection, nanoparticles

\section{References:}

[1] Silva BA, Oliveira PJ, Cristóvão A, Dias ACP, Malva JO. Biapigenin Modulates the Activity of the Adenine Nucleotide Translocase in Isolated Rat Brain Mitochondria. Neurotox. Res. 2010; 17: 75 - 90.

[2] Silva BA, Dias ACP, Ferreres F, Malva JO, Oliveira C. Neuroprotective Effect of H. perforatum Extracts on $\beta$-Amyloidinduced Neurotoxicity. Neurotoxicity Res. 2004; 6:119 - 130. 